\title{
LA VIOLENCIA DICTATORIAL DEL CONO SUR Y SUS HERIDAS SIN CICATRIZ*
}

Mariela Ávila ${ }^{+}$

* Este trabajo forma parte del Proyecto Postdoctoral FONDECYT Nº 3140089 "Análisis filosófico de los campos de prisioneros del Cono Sur a partir de los aportes de Hannah Arendt y Giorgio Agamben", y del Proyecto FONDECYT Regular No 1140200. "Campos de prisioneros en Chile. Reconfiguración de los lugares y las subjetividades".

† Doctora en Filosofía por la Pontificia Universidad Católica de Valparaíso y por Paris 8 Saint-Denis. Postdoctoranda FONDECYT, IDEA, USACH, Chile. marielnauta@yahoo.com.ar 


\section{A MODO DE INTRODUCCIÓN}

En el presente artículo busco presentar parte de mis investigaciones filosóficas relativas a las últimas dictaduras militares del Cono Sur latinoamericano que tuvieron lugar en el último tercio del siglo pasado. Y si bien se parte de la indagación de elementos -tal como se mostrará a lo largo del trabajo-, que extienden una reflexión común a los procesos histórico-políticos que acontecieron en Chile, Argentina y Uruguay, en este escrito en particular, se asentará la atención principalmente en el caso chileno. No obstante, esto no implica desconocer las semejanzas con el resto de los países de la región, ni evitar las menciones y referencias cuando sea el caso.

En principio, aclaro que no es mi intención entrar en una discusión sobre los grados de responsabilidad y culpas, equiparando las acciones violentas del Estado con la de las organizaciones clandestinas. En primer lugar, porque considero que son fenómenos de diversa raigambre, por lo que identificar comparativamente acciones sin una mediación previa puede resultar confuso e incluso peligroso; y en segundo lugar, pero no menos importante, porque tal discusión no tiene relación con mis intereses investigativos. En efecto, considero que el despliegue de dicha discusión ha arrojado pocas luces al desarrollo de una reflexión profunda y crítica sobre las dictaduras del Cono Sur y sus consecuencias.

Desde una perspectiva teórica, la matriz de análisis del presente trabajo tiene una clara raigambre biopolítica, pues se asienta en una reflexión sobre la violencia desde la categoría de población a partir del registro de la regulación, gestión y administración de la vida. La categoría de violencia, en tanto signatura de este contexto histórico-político, será la que guíe este escrito, 
abriendo un ámbito en donde se podrá observar el cruce entre un modo de administración biopolítico de las poblaciones, y prácticas disciplinares institucionales que recaen sobre individualidades. En este contexto, la figura del campo de concentración como dispositivo estatal, será el ámbito topográfico y topológico que ampliará el registro de análisis y permitirá apreciar con mayor claridad el cruce entre lo individual y lo poblacional.

A partir de lo anterior, busco inscribir este trabajo en los límites des-limitados -si se me permite-, de la filosofía política, pues a partir de la caja de herramientas conceptual otorgada por esta disciplina, inicio una reflexión mediada por otros saberes, que busca dar cuenta de la violencia como un fenómeno político propiciado y amparado por Estados dictatoriales. Por este motivo será importante atender a los cruces entre los distintos campos del saber, cobrando en esta trama especial relevancia la historia, la antropología, la sociología y la literatura testimonial.

Ahora bien, en este pequeño texto pretendo dar un paso más allá en mi propia investigación, pues aunque considero un ejercicio necesario llevar a cabo un análisis sobre nuestro reciente pasado político, también creo que lo es pensar sus rastros y efectos, aquellos que perduran aún hoy y que se diseminan sobre nuestro presente. En ese sentido, sostengo que la violencia dictatorial no acabó con el retorno de la democracia a la región, sino que por el contrario, a partir de procesos de metamorfosis y maquillajes, ha modificado su apariencia sin desaparecer. Así, la violencia estatal en nuestros días se ampararía bajo máscaras legalistas y legitimadas, que en muchos casos, esconderían tras de sí el paradigma de la violencia del Estado militar. No desarrollaré aquí un análisis comparativo de casos, pero sí se reflexionará sobre 
el modo en que ciertas prácticas y dispositivos estatales propios de la dictadura han perdurado en el tiempo, ejerciendo aún hoy violencia y terror sobre la población.

Espero entonces que las investigaciones que aquí presento, se vean enriquecidas al compartir este espacio de reflexión con trabajos que analizan otras experiencias y sucesos histórico-políticos relativos a otros países latinoamericanos. Confío en que este escrito cobre mayor sentido en el presente corpus de artículos, posibilitando una reflexión en vistas al conjunto, lo que permitiría extender la indagación a un nivel más amplio. Esto habilitaría a pensar que hay momentos en que las distancias geográficas parecen acortarse, y que cuando de reflexionar sobre la violencia e injusticia se trata, los límites se corren, y la vida desnuda queda expuesta, mostrando que ciertos modos de racionalidad gubernamental no distinguen geografías, soberanías ni fronteras. Sin embargo, es esta misma lógica la que nos permite incluir modos de resistencia y subjetivación política como elementos comunes a nuestros países ante tales formas de poder gubernamental. Comenzamos así una indagación que más allá de conclusiones y cierres, busca mostrar aperturas y nuevos caminos para una reflexión de carácter situado.

\section{EXCEPCIONALIDAD Y VIOLENCIA: EL PAPEL DEL ESTADO}

Para comenzar el análisis, diremos que probablemente, una de las primeras ideas que aparece al momento de reflexionar sobre las dictaduras militares del Cono Sur sea la de violencia. En efecto, al pensar en estos sucesos histórico-políticos, el relieve de la imagen que se hace patente muestra una amalgama entre violencia, terror, muerte y tortura. Sin embargo, esta imagen no es solo simbólica o conmemorativa, pues sus rastros y restos se evidencian en las cicatrices aún abiertas que recorren nuestros 
países, y que trazan fronteras y límites tangibles al interior del cuerpo de la población.

Este trabajo busca entonces, acercarse a la figura de la violencia dictatorial y a sus efectos en el cuerpo de la sociedad actual, amparados aún en dispositivos de tortura y terror. En miras a esto, interesa destacar de modo particular que la violencia de los gobiernos dictatoriales fue ejercida desde y por el aparato estatal, lo que implementó una institucionalidad plena de discursos, prácticas y dispositivos para ejercer el terror. En esta línea, el presente escrito tendrá en cuenta aquellos dispositivos estatales del ejercicio de la violencia y el terror por antonomasia: los campos de concentración, también llamados centros clandestinos de detención*. A lo largo de este trabajo ambos términos serán utilizados para hacer referencia a estos ámbitos donde se vislumbra con total claridad la puesta en práctica de discursividades y ejercicios de violencia.

Como se indicó al principio, si bien al reflexionar sobre el problema de la violencia en el Cono Sur, encontramos elementos comunes a los tres países, es decir, a Argentina, Chile y Uruguay; sin embargo, se atenderá aquí de modo particular al caso de la dictadura chilena. Así, a partir de la diferenciación entre elementos políticos comunes internos y externos que desarrolla Raffin (2006), analizaremos el recurso al estado de excepción, como posibilitante de la suspensión de la legalidad. Es Carl Schmitt ${ }^{\dagger}$

\footnotetext{
* Esta problemática ha sido abordada con mayor profundidad en los siguientes artículos: Avila, M. (2013). Estado de excepción y campos de concentración en Chile. Una aproximación biopolítica. Revista Sociedad Hoy. Departamento de Sociología y Antropología. Universidad de Concepción, Concepción. Número 25, y Avila, M. (2013). Campos de concentración de las dictaduras latinoamericanas. Una mirada filosófica. Revista La Cañada. Pensamiento Filosófico Chileno. No 4.

† Jurista y filósofo alemán, afiliado al Partido Nacionalsocialista que buscó dar un marco de legilitimad al Régimen Nazi.
} 
quien define de la siguiente manera el estado de excepción: "El caso excepcional, no descrito en el orden jurídico vigente, puede a lo sumo definirse como un caso de necesidad extrema, de peligro para la existencia del Estado o algo semejante (...)" (Aguilar, 2001, p.23). La necesidad extrema implica una suspensión temporal de la legalidad, propiciando la llegada de una fuerza de ley sin legitimidad al poder, a fin de aplacar el caso excepcional y garantizar la posterior continuidad de la estabilidad del Estado. A partir del recurso a la excepcionalidad, el cuerpo legal cae, se suspende el ámbito jurídico y la autoridad es asumida por quien oficie de soberano. En estos periodos, el gobierno se apoya en bandos y decretos con fuerza de ley para regir el país. Es precisamente en estos momentos de anomia cuando la vida de la población queda desprotegida ante una violencia en potencia, y pueden aparecer aquellos dispositivos estatales llamados campos de concentración.

En el caso de Chile, el golpe de Estado tuvo lugar el 11 de septiembre de 1973, dejando como saldo miles de muertos, entre ellos el Presidente de la nación, Salvador Allende. El gobierno militar produjo un quiebre en la legalidad de la nación, sumiendo al país en una excepcionalidad que se extendió durante 17 años. Es decir, que desde el año1973 cuando fue derogada la Constitución de 1925, hasta 1990 cuando entró en vigencia la Constitución del 80, no hubo un marco legal que rigiera al país. Durante este período, la nación chilena estuvo gobernada por múltiples bandos militares, que adquirieron la forma de decretos con fuerza de ley, cuya función era la de otorgar una suerte de institucionalidad a la des-institucionalización del país. Es decir, la tarea de los edictos y decretos era brindar un marco de legalidad a la ilegalidad del gobierno imperante. La normatividad institucional estaba dada por bandos que buscaban legitimar la existencia y las acciones de un Estado terrorista. 
Ahora bien, es importante tomar en cuenta el valor extra-jurídico de estos designios militares, pues su valor simbólico es también un claro determinante gubernamental. Así, tal como indican Garretón, Garretón \& Garretón (1998):

(...) la funcionalidad normativa de los bandos no se agota en esta generación de una institucionalidad del golpe y de los actos de la junta militar, sino que abarca las conductas de la vida cotidiana, tanto para castigar y reprimir, como para premiar y fanatizar. (p.18)

Los bandos militares, sobre todo en los primeros meses que siguieron al golpe, fueron los lineamientos para la construcción de una nueva nación chilena que promulgaba valores políticos, económicos, sociales, morales y sexuales, de carácter occidental y cristiano. $Y$ es en estos designios militares, donde se evidenciaba con mayor claridad la necesidad de eliminar a un enemigo político interno, que se oponía y dificultaba el surgimiento de la nueva nación.

En este punto me interesa remarcar que no fue una fuerza externa a la sociedad y al Estado la que implementó políticas de terror, violencia y muerte, sino que al contrario, fue la anulación de la legalidad la que permitió a una parte de la población erigir un Estado opresor, que asumió como propia la tarea de torturar, hacer desaparecer y dar muerte a la disidencia política. En este sentido, Raffin (2006) indica que: "(...) las dictaduras del Cono Sur se apoyaron, al tiempo que construyeron, un Estado terrorista que fue acompañado necesariamente por la instauración de un cierto modelo social y por una cultura del miedo" (pp.157158). Esta cultura del miedo fue precisamente la que propició la construcción de un "otro", en tanto enemigo, que era necesario aniquilar en pos de la paz y el bien común. 


\section{SACRIFICABILIDAD DE LOS CUERPOS:}

\section{EL LUGAR DEL OTRO}

Es interesante notar que el Estado terrorista chileno, a través de mecanismos, discursos y dispositivos, hizo uso de la noción de guerra, enfatizando la existencia de un enemigo interno cuyo peligro ameritaba su destrucción. Para llevar a cabo tal fin, se erigieron los campos de concentración y exterminio, donde la violencia se llevó a extremo, recayendo sobre los cuerpos particulares de los prisioneros y militantes políticos. Estos espacios concentracionarios, que se constituyeron al margen de la legalidad, no operaban como cárceles comunes en donde hay individuos que han pasado por un proceso legal y han sido juzgados por algún delito cometido. Por el contrario, la marca principal de estos ámbitos es la ilegalidad, que amparada en la excepcionalidad vigente, expulsa del sistema jurídico a aquellas corporalidades que por motivos políticos deben quedar erradicadas de la unidad del cuerpo social.

En esta línea, es interesante notar que en el caso de las dictaduras del Cono Sur, el blanco del terror no fueron tan solo los militantes políticos, sino que casi cualquier miembro de la sociedad podía convertirse en un eventual secuestrado, torturado y desaparecido. Así, relaciones de parentesco, de amistad, o incluso el azar de encontrarse en cierto lugar en un momento equivocado, eran variables suficientes para que cualquier persona fuese privada de su libertad, para ser interrogada a través de vejaciones, y posiblemente, no volviera a aparecer. Si nos fijamos en los testimonios y escritos relativos a estos períodos, un gran número de ellos da cuenta de la aleatoriedad que implicaba el proceso de privación de la libertad, en el que incluso se llega a notificar la detención de enfermos mentales, mendigos y niños. 
Precisamente, el contexto socio-político propiciaba estas prácticas afincadas en la violencia y el terror, pues como indican Garretón et. al., (1998), refiriéndose a la etapa inmediatamente posterior al golpe militar: "No podía darse (...) un golpe de Estado sin un posterior estado de golpe" (p.10). Fue precisamente dicho estado general de golpe el que sumió al pueblo chileno en una trama de muerte, violencia y terror, posicionando a algunos de sus miembros en el lugar de un "otro" que se debía encerrar, interrogar, torturar, aniquilar y finalmente, hacer desaparecer.

El cuerpo de ese "otro", representado por la disidencia política, pero que como se indicó alcanzó al tejido de la sociedad en general, fue el paño sobre el que se trazaron los peores castigos y tormentos, fue la materia que se quiso borrar de la faz de la tierra, no sin antes haberla humillado hasta el cansancio, negándole toda cuota de humanidad. Quienes pasaron por estos espacios y sobrevivieron, atravesaron por un proceso de "formateo" como indica Pilar Calveiro (2008), cuyo fin fue la destrucción progresiva de la subjetividad, la personalidad y finalmente la humanidad.

Así, los campos de concentración en el Cono Sur latinoamericano sirvieron, tal como indica Arendt (1987) en relación a los lager nazis, de laboratorios de la muerte, donde tuvo lugar una experimentación sobre la vida, el terror y el dolor a partir del uso descarnado de la violencia. Esto a tal punto, que las situaciones allí acontecidas en muchos casos parecen despegarse de la realidad y encarnar un relato de ficción. En este sentido, el corpus (Agamben, 2003) de la población -en tanto ámbito en que se ejerce físicamente la política-, fue el centro del sacrificio, la materia en donde se evidenció que "todo es posible" (Rousset, 2003), incluso lo impensable. 


\section{LA MIRADA BIOPOLÍTICA}

Foucault (2003) en el primer volumen de la Historia de la sexualidad. La voluntad de saber, introduce la noción de biopolítica, para aludir al poder que se ejerce sobre la vida, esta vez no desde la individualización como en el caso de la disciplina, sino a partir de la figura de la población. No es solo la normación unificadora el elemento que actuará aquí, sino que operan mecanismos de regulación y administración de la vida. Dichas mecánicas tienen como fin inducir y lograr efectos sociales y políticos deseados.

El poder soberano que decidía sobre la vida a través de la muerte, queda recubierto ahora por un poder vital que promulga la continuidad de la existencia bajo ciertos parámetros y condiciones. El blanco del poder es la población, y no ya el cuerpo individual que vigilaban y controlaban las diversas instituciones. Se buscará entonces regular a esta en su totalidad, actuando sobre aquellos rasgos comunes y naturales que comparten los hombres, tales como nacimiento, enfermedades, sexualidad, muerte, entre otros. La meta de la estructura biopolítica es la administración y extensión de la existencia, es decir, el cuidado y el manejo de la vida desde todos sus parámetros y ámbitos.

No obstante, este contexto de cuidado de la vida no permanece ajeno a la violencia y la muerte. En efecto, aquellas existencias que no se ajustan a los parámetros y regulaciones impuestas por el Estado se convierten en un elemento molesto, que debe ser aniquilado o expulsado de alguna manera del cuerpo social. El recurso que muestra Foucault para tal fin es el de "racismo de Estado" (Foucault, 2001), en tanto mecanismo que genera cesuras al interior del cuerpo social, marcando una diferencia entre aquellas vidas consideradas dignas, y aquellas que no lo son, lo 
que amerita su eliminación. Un elemento importante a considerar respecto a este recurso, y sobre todo en nuestro contexto y caso de análisis, es que cuando Foucault habla de aniquilación y muerte en relación al racismo de Estado, no se refiere solo a la muerte física, sino también a la falta de reconocimiento y a la expulsión social, lo que caracteriza como una muerte política. De esta manera, condiciones indignas de existencia, falta de valía política, falta de reconocimiento, desamparo legal y social, son algunas de las formas que adquieren nuestros Estados para deshacerse de aquellas vidas consideradas superfluas, esas existencias que de alguna u otra manera interfieren en el desarrollo del Estado protector de ciertas formas de vida.

Sin embargo, tomando como punto de análisis nuestro problema en particular, es posible observar con bastante claridad las dos formas de poder sobre las que habla Foucault -disciplina y biopolítica-, operando sobre los cuerpos de la población durante el período de dictadura militar en Chile. En efecto, durante los gobiernos militares se observa la imbricación entre una forma de poder asentada en el cuerpo individual y otro modo de administración relativo a la regulación de la existencia a nivel poblacional.

Aludir a la categoría de cuerpo permite establecer una reflexión respecto al cuerpo físico de cada individuo particular sobre el que recae la violencia, así como también pensar el cuerpo social de la población como blanco de poder. En efecto, en estos contextos ambos cuerpos son moldeados y sacrificados en pos de una unidad nacional que no admite diferencias ni disidencias. La figura del sacrificio evidencia las torsiones que sufre la vida tanto en sus aspectos individuales como poblacionales y sociales, pues tal como indica Arendt (1987), durante ciertos períodos políticos, 
la vida en su totalidad queda invadida, siendo blanco tanto de una fuerza a nivel físico, como de una fuerza simbólica a nivel discursivo que se instala en las tramas políticas y sociales. Observamos entonces, que en durante la última dictadura militar en Chile operó un poder de carácter segregador, que recayó sobre el cuerpo individual de los prisioneros a través de prohibiciones, controles, torturas y vejámenes, y a la vez un poder masificador, que reunió los cuerpos de la población en una unidad, aplicando políticas y prácticas violentas que conducían, mediante la aplicación del terror, a ciertos modos de vida y rentables para las juntas militares y el país que se buscaba refundar.

Es precisamente Arendt (1993) quien en su lúcida reflexión sobre el totalitarismo muestra la necesidad de estos gobiernos de convertir a los hombres en algo diferente de sí mismos, en una igualdad biológica originaria que les reste todo rasgo de humanidad y los convierta en un cúmulo de necesidades vitales sin reacciones*. En esta línea, y reconociendo la diferencia entre gobierno totalitario y dictadura militar, es posible ver aún que los estados terroristas del Cono Sur buscaron, precisamente, aniquilar la humanidad de los prisioneros mediante técnicas de tortura y violencia aprendidas en escuelas de entrenamiento militar internacionales. Estos procesos de desubjetivación sobre la población implicaron una notable reconfiguración de los lazos y de las relaciones sociales, instalando el miedo como factor principal, lo que es posible observar aún hoy en la población chilena, incluso en las democracias actuales. En este sentido, podemos acudir a la reflexión de Benjamin (1996) que indica de que la excepción

* "Ellos no morían en calidad de individuos, es decir de hombres y de mujeres (...) sino que ellos fueron reducidos al más pequeño denominador común de la vida orgánica (...)" [La traducción es mía]. 
deviene norma, y que aquellas prácticas y operaciones que tenían un carácter provisorio, se convierten en algo cotidiano que ni siquiera admite interrogación. El Chile actual se ha configurado en tanto heredero de la violencia y el terror alcanzados durante estos periodos políticos, que lejos de haber desaparecido con el fin de los gobiernos militares, se han metamorfoseado hasta alcanzar otras prácticas y estatutos, pero de igual raigambre, sobre la población.

\section{EL HOY DE LA VIOLENCIA ESTATAL: UNA POSIBLE REFLEXIÓN}

Tal como indiqué en la primera parte de este trabajo, avanzando en mi propia investigación, intentaré vislumbrar posibles nexos entre la violencia dictatorial, y la actual de los períodos democráticos. Esta es entonces la parte más arriesgada de mi trabajo, pues implica efectuar un diagnóstico del presente a la luz del pasado, mostrando el modo en que determinados modos del uso de la violencia dictatorial se encuentran hoy presentes en nuestros gobiernos. En este sentido, me interesa dar cuenta del modo en que las formas de violencia reguladas estatalmente han pasado por transformaciones y cambios que aún las mantienen vigentes, por lo que conservan su incidencia tanto sobre la población, como sobre la subjetividad y los cuerpos de los individuos.

Así, este diagnóstico parte de la hipótesis que indica que en las democracias actuales no nos encontraríamos frente a nuevas formas de terror y violencia, sino que por el contrario, estas, en gran medida, son el resultado de aquellas impuestas durante los gobiernos militares. Quizá sea necesario aclarar que con esto no me refiero a que las instituciones y los mecanismos del Estado terrorista sobrevivan impolutos en la actualidad, pero sí que sería posible observar sus rastros y efectos en prácticas y discursos presentes. 
En esta línea podríamos sostener que la necesidad de aniquilación de un "otro", en relación al recurso del racismo de Estado presentado por Foucault, de alguna manera sigue operando en los gobiernos democráticos de la región. La violencia estatal ha mutado, se ha sofisticado, ha adquirido otros rostros y matices, pero bajo sus máscaras continúa arraigada la fuerza del Estado terrorista. $Y$ es precisamente en momentos considerados excepcionales cuando la violencia emerge en plenitud, haciendo evidente una vez más que los cuerpos son sacrificables, y que la estabilidad democrática guarda dentro de sí una cuota de caos y terror, que bien pueden materializarse y operar hoy en día sobre la totalidad de la población.

Como se indicó con anterioridad, luego del golpe militar de 1973, Chile permaneció 17 años sin que rigiese una constitución, esto es, hasta el año 1990, cuando se derogó la Constitución del 80 cuyo principal ideólogo fue el jurista Jaime Guzmán. Este abogado, al igual que lo hiciera Carl Schmitt respecto al régimen nazi, intentó dar un marco de legalidad a una forma de gobierno asesino e ilegítimo. Guzmán, gran admirador de Schmitt, buscó restar el peso real que tenía la violencia, tortura y desaparición de los disidentes políticos, apoyándose en la dicotomía schmittiana de "amigo-enemigo", lo que en última instancia, permitía, e incluso normalizaba, prácticas terroristas contra los enemigos de la nación*.

Es interesante notar que dicha Constitución, entre sus artículos, amarra la continuidad del régimen militar al poder desde diversos

* Véase: Cristi, R. (2011). El pensamiento político de Jaime Guzmán. Una biografía intelectual. LOM Ediciones, Santiago de Chile. 
espacios. Ejemplo de ello es la prolongación de la ola de privatizaciones a la que se había sumido al país durante la dictadura en diversos ámbitos, tales como el educativo o el de la administración y explotación de los recursos naturales. A su vez, este código que impone una férrea conducta moral, sexual y social, prohíbe el aborto bajo cualquier circunstancia, práctica que en Chile antes de 1973 y en determinadas circunstancias, era legal. La Constitución del 80 aseguró la continuidad del poder militar en los lineamientos primordiales del país, en el ámbito económico, moral, social, y por supuesto, político. Rodríguez (2011) muestra las intenciones que tuvo Pinochet con la promulgación de esta carta magna:

Allí, se buscaba prefijar los parámetros de su sucesión y asegurar su continuidad mediante un largo periodo de transición (...) en el que las libertades individuales se restringirían como producto de las facultades extraordinarias que se le otorgaban al dictador. (p.146)

Dado lo anterior, sostenemos que en el caso de Chile la llegada de la democracia no implicó el distanciamiento total de las fuerzas militares, ni siquiera luego del proceso de transición, sino que por el contrario, la Constitución de 1980 que aún rige al país, da cuenta que en el centro de la democracia permanecen latentes el poder y la violencia dictatorial. Incluso, hay leyes que evidencian la matriz violenta de la legalidad chilena, como por ejemplo la Ley Antiterrorista 18.314, decretada en el año 1984, entre cuyas prerrogativas se encuentra la posibilidad de hasta cuadriplicar las penas de los juzgados*. Quienes comparecen ante esta ley son juzgados por una corte militar y no por una civil, como

* Véase: Ávila, M. (2012). El cuerpo como lugar de la utopía. Estudios de Filosofía Práctica e Historia de las Ideas. [online], vol.14, n.2, pp. 9-16. ISSN 1851-9490. 
el resto de la población. El pueblo Mapuche es el más afectado por la continuidad de esta ley, pues esta etnia a la que no se le otorga derecho de autodeterminación, es juzgada con leyes diferentes al resto de los chilenos. Es decir, la continuidad de esta Constitución evidencia la fuerza de la excepcionalidad operando dentro del Estado democrático, lo que conduce, una vez más, a la necesidad de aniquilar y hacer desaparecer aquellos elementos considerados desintegradores de los procesos organizacionales de la nación. El racismo de Estado foucaulteano se hace patente con toda su fuerza aquí, mostrando el ejercicio de un poder disciplinar y de un accionar biopolítico imbricados sobre la población. El pueblo Mapuche es esta vez el elemento subversivo que hay que aniquilar, o al menos apaciguar, pues es el componente que impide la síntesis del todo al no integrarse dócilmente como una de sus partes.

En este sentido, la continuidad en vigencia de esta ley demuestra que la excepcionalidad como recurso político sigue operando, a la vez que manifiesta la fragilidad de una democracia que aún considera cierta parte de la población y ciertos cuerpos como superfluos y sacrificables. Es interesante notar sin embargo que la Ley 18.314, (2010) que hoy juzga al pueblo Mapuche, puede situar a cualquier elemento opositor en su centro: estudiantes, trabajadores portuarios, anarquistas, es decir, cualquier individuo o grupo que altere la aparente paz democrática y demuestre que el corazón del Estado está pleno de violencia.

Así, el terror y la violencia han mutado, han cambiado sus rostros, se han diversificado bajo una aparente docilidad legal, pero sin embargo, y acudiendo a la metáfora hobbesiana, el lobo está siempre latente. Precisamente, el estado de naturaleza puede emerger en aquellos momentos considerados excepcionales, que no obstante cada vez cobran un mayor estatuto de normalidad, 
porque tal como lo indican las visionarias palabras de Benjamin (1996):

La tradición de los oprimidos nos enseña que el «estado de excepción» en que vivimos es la regla. Tenemos que llegar a un concepto de historia que le corresponda. Entonces estará ante nuestros ojos, como tarea nuestra, la producción del verdadero estado de excepción; y con ello mejorará nuestra posición en la lucha contra el fascismo. (p.56)

\section{A MODO DE CONCLUSIÓN}

La incipiente reflexión que aquí se presenta ha pretendido evidenciar un nexo tangible entre la violencia dictatorial y la violencia presente en la democracia actual en el caso de Chile. En esta línea se analizó el modo en que la fuerza de la excepcionalidad que considera ciertas vidas vejables y sacrificables, continúa vigente en el corazón de la legalidad, restando valía política y humanidad a la existencia de una parte de la población.

En este sentido, considero que la violencia en las actuales sociedades democráticas actúa en cierta forma como un significante vacío en sentido lacaniano, pues puede colocar en su centro diferentes elementos que considere "subversivos" o nocivos, poniendo en marcha una cadena de terror, violencia y muerte. Las vidas que quedan incluidas a través de su exclusión en el centro de esta legalidad exceptuante, se encuentran en potencia de ser vejadas, aniquiladas y desaparecidas aún hoy, en democracia. Es decir $-y$ esto puede notarse a partir de lo analizado en el caso chileno-, en el centro de la constitución democrática afinca una violencia terrorista, que en última instancia, es la que ha forjado un presente legitimado y legalizado desde su excepcionalidad.

Pareciera ser entonces, que tal como indica Bourne (2012) en 1918 refiriéndose a Estados Unidos, "La salud del Estado es la 
guerra": una guerra que puede ser explícita, pero también subterránea, recubierta de una aparente tranquilidad y legalidad, pues el estado de guerra, que requiere de un enemigo convertido en "otro", da la posibilidad de aniquilar en tiempos de paz. Podríamos pensar entonces que lo que da unidad a los Estados-nación, y que mantiene una supuesta coherencia democrática es precisamente el cuerpo de ese "otro" que es necesario expulsar y aniquilar: contra él se alinean una serie de dispositivos y prácticas que legitiman la violencia, la muerte y la desaparición.

Creo que es lícito interrogar hoy por el legado de la dictadura militar, pues valdría preguntarse si la herencia de la violencia dictatorial es solo eso, una herencia, o si es una práctica que permanece latente, y que puede emerger en cualquier momento. Incluso, y yendo más lejos aún, se podría pensar que la excepcionalidad es la aparente democracia, y que la norma está dada por la violencia y el terror constantes. Sin embargo, por el momento estas son solo elucubraciones que requieren de un mayor desarrollo, pero que de todas maneras me interesa plantear.

Para finalizar tomaré prestadas las palabras del testimonio Cerco de Púas, de Quijada (1990), quien dice respecto a su salida del campo de concentración:

Comprendí después que no era libre. Había un cerco de púas que salía de los centros de detención y se prolongaba afuera rodeando la ciudad. Podía verse en las calles alrededor de cada casa, circundando a las personas con sus púas bien dispuestas. (p.173)

Extremando a Quijada (1990) tal vez podríamos decir que ese cerco de púas es la violencia dictatorial que se extiende aún hoy, rodeando las ciudades y los individuos, adquiriendo otras formas y desplegándose bajo nuevos modos y apariencias cargadas de 
legalidad y hasta de amabilidad, pero aún con sus púas bien dispuestas. Deberemos entonces, tal como indica Benjamin (1996), estar atentos a las metamorfosis de la violencia dictatorial, a fin de generar un verdadero estado de excepción para distinguir su ejercicio bajo todas las capas de maquillaje, lo que nos permitirá, en última instancia, identificarla y continuar luchando contra ella.

Así concluyo este breve escrito que ha pretendido dar pie a una reflexión filosófica sobre la violencia dictatorial y sus despliegues en nuestro presente. En efecto, lo que he presentado aquí intenta mostrar posibles modos de abordar ciertos acontecimientos histórico-políticos, que lejos de estar sepultados en el pasado nos constituyen, a la vez que nos interpelan en el hoy de nuestro quehacer cotidiano.

\section{REFERENCIAS BIBLIOGRÁFICAS}

Agamben, G. (2003). Homo sacer. El poder soberano y la nuda vida. Valencia, España: Pre-Textos.

Aguilar, H. (2001). Carl Schmitt, teólogo de la política. México:

Editorial Fondo de Cultura Económica.

Arendt, H. (1987). Los orígenes del totalitarismo. Madrid, España: Alianza.

Arendt, H. (1993). L'image de l'enfer. En: Auschwitz et Jérusalem. París: Deux Temps Tierce.

Ávila, M. (2013). Campos de concentración de las dictaduras latinoamericanas. Una mirada filosófica. Córdoba, Argentina: La Cañada.

Ávila, M. (2013). Estado de excepción y campos de concentración en Chile. Una aproximación biopolítica. Sociedad Hoy. Chile: Universidad de Concepción.

Benjamin, W. (2002). La dialéctica en suspenso. Fragmentos sobre la historia. Chile: Editorial Arcis-Lom. 
Bourne, R. (2012). La santé de L'État, c'est la guerre. Quetigny, Francia: Éditions le passager clandestin.

Calveiro, P. (2008). Poder y desaparición. Los campos de concentración en Argentina. Buenos Aires, Argentina: Colihue.

Calveiro, P. (2012). Violencias de Estado. Buenos Aires, Argentina: Siglo XXI.

Congreso de Chile. (8 de octubre de 2010). Ley que determina conductas terroristas y fija su penalidad. [Ley 18.314 de 2010]. DO: 08.10.2010.

Cristi, R. (2011). El pensamiento político de Jaime Guzmán. Una biografía intelectual. Santiago de Chile, Chile: LOM Ediciones.

Foucault, M. (2001). Defender la sociedad. Buenos Aires, Argentina: Fondo de Cultura Económica.

Foucault, M. (2003). Historia de la sexualidad. La voluntad de saber. Buenos Aires, Argentina: Siglo XXI.

Garretón, M., Garretón, R. \& Garretón, C. (1998). Por la fuerza sin la razón. Análisis y textos de los bandos de la dictadura militar. Santiago de Chile, Chile: LOM Ediciones.

Quijada, A. (1990). Cerco de púas. Un candente testimonio sobre la represión. Santiago de Chile, Chile: Editorial Fuego y Tierra. Raffin, M. (2006). La experiencia del horror. Subjetividad y derechos humanos en las dictaduras y postdictaduras del Cono Sur. Buenos Aires, Argentina: Del Puerto.

Rodriguez, J. (2011). El caso Chile. La Guerra Fría y la influencia argentina en la transición democrática. Buenos Aires, Argentina: Capital Intelectual.

Rousset, D. (2003). L'univers concentrationnaire. Paris, Francia: Pluriel. 